\title{
Flip angle optimization for quantitative phase contrast MR imaging
}

\author{
Daniel B Ennis*, Matthew J Middione \\ From 2011 SCMR/Euro CMR Joint Scientific Sessions \\ Nice, France. 3-6 February 2011
}

\section{Objective}

The overall objective of the work proposed herein is to optimize the flip angle in gradient-echo based PC-MRI methods for decreased measurement variability in quantitative blood velocity measurements of the common femoral arteries.

\section{Background}

PC-MRI is a noninvasive imaging technique used to measure the velocity of flowing blood in a particular blood vessel with flexible spatial and temporal resolution $[1,2]$. It is considered the clinical "gold standard" for quantification of blood flow. PC-MRI boasts a variety of established applications in quantifying cardiovascular function and hemodynamics. In particular, this technique offers clinicians with a means of measuring peak velocity, mean velocity, flow rate, and total flow throughout the vasculature of the human body. One of the challenges in PC-MRI is the wide range of variables that make up a given protocol requiring careful optimization of each imaging parameter in an effort to accomplish the goals of a given scan. Surprisingly, the current PC-MRI utilizes a default flip angle, which has not been optimized. A theoretical description of the signal acquired from flowing spins in spoiled gradient-echo pulse sequences has been previously developed [3]. These efforts indicate that there exists a flip angle that provides an optimized SNR for a given tissue, echo time, repetition time, slice thickness and velocity, which leads to increased reproducibility of quantitative PC-MRI measurements. This optimization cannot be performed empirically because of the number of parameters involved, hence mathematical and computation work is required.

University of California, Los Angeles, Los Angeles, CA, USA

\section{Methods}

All measurements were performed on a 1.5 Tesla system (Avanto; Siemens Medical Solutions, Erlangen, Germany) using a 16-channel surface coil. Blood velocity data in the common femoral arteries were obtained in 5 healthy consenting volunteers ( 4 male, 1 female, age _ \pm _ years). PC-MRI was performed without breathhold using retrospective ECG triggering. Imaging parameters included $340 \times 212.5 \mathrm{~mm}$ field of view, $256 \mathrm{x}$ 160 matrix, $1.3 \mathrm{~mm}$ isotropic resolution, $8 \mathrm{~mm}$ slice thickness, 5.4/3.2 msec TR/TE, $32.4 \mathrm{msec}$ temporal resolution, a range of flip angles for optimization $\left(5,10,15,20,30,40,60,75\right.$ and $\left.90^{\circ}\right), 888 \mathrm{~Hz} /$ pixel acquisition bandwidth, three views per segment and a velocity encoding strength of $75 \mathrm{~cm} / \mathrm{sec}$ (53 second scan time). The imaging was repeated 5 times in each volunteer.

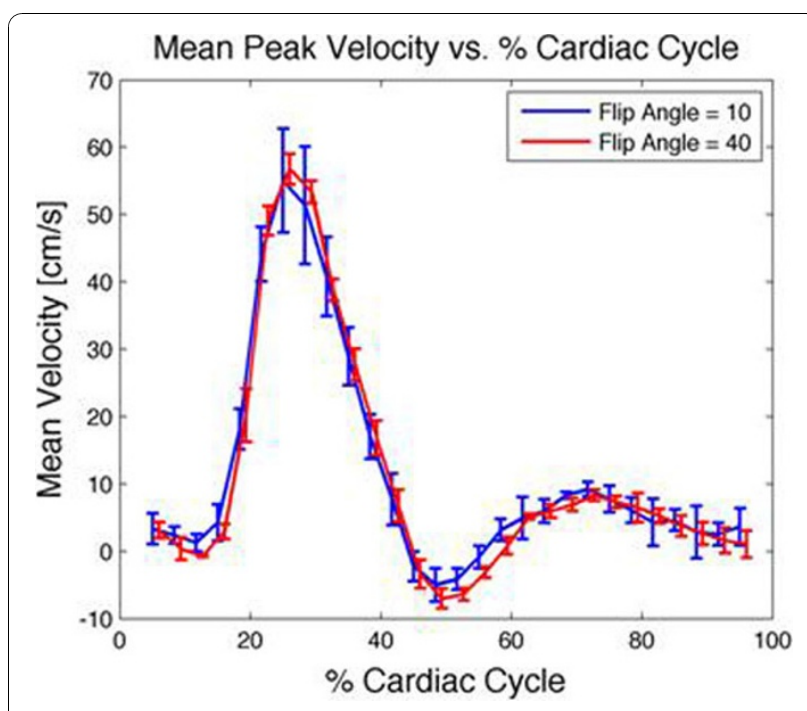

Figure 1
() 2011 Ennis et al; licensee BioMed Central Ltd. This is an open access article distributed under the terms of the Creative Commons Attribution License (http://creativecommons.org/licenses/by/2.0), which permits unrestricted use, distribution, and reproduction in any medium, provided the original work is properly cited. 


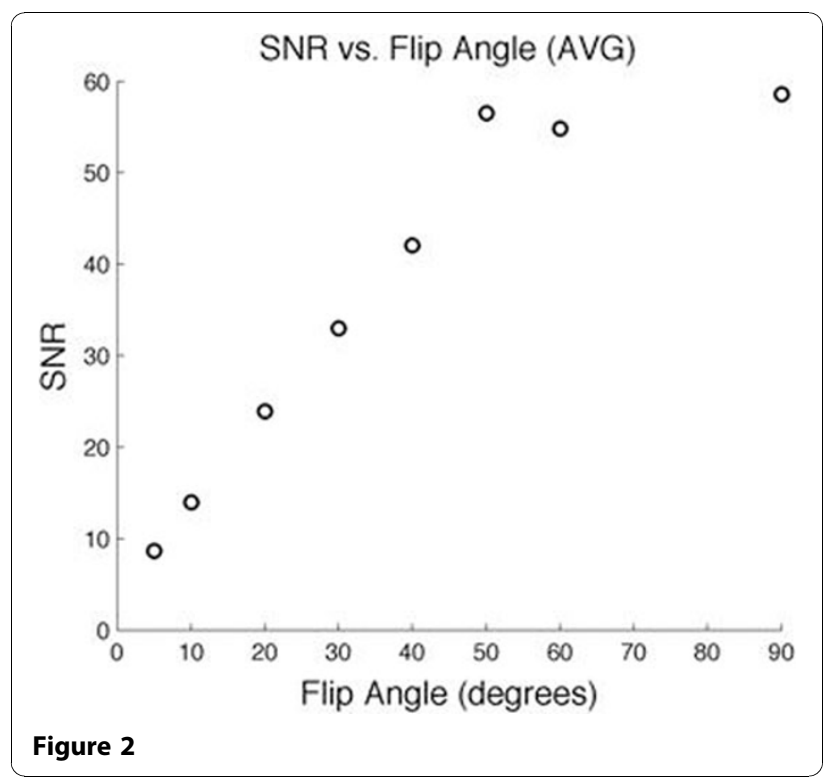

\section{Results}

The results indicate that there exists an optimal flip angle (Figure 1) in which the SNR is optimized for a given experiment. The use of this flip angle yields decreased variability in quantitative blood flow measurements compared to other non-optimized flip angles (Figure 2). From these results it can be concluded that careful selection of the flip angle is required. Flip angles for flow quantification are not sequence dependent; rather they are velocity dependent for a given protocol and simply selecting a default flip angle for any given study will not be sufficient to yield the best results.

\section{References}

1. Pelc NJ: Magn Reson Imaging 1995, 3:413-424.

2. J Lotz J, et al: Radiographics 2002, 22:651-671.

3. Gao JH, et al: Medical Physics 1988, 15:809-814.

doi:10.1186/1532-429X-13-S1-P67

Cite this article as: Ennis and Middione: Flip angle optimization for quantitative phase contrast MR imaging. Journal of Cardiovascular Magnetic Resonance 2011 13(Suppl 1):P67.

Submit your next manuscript to BioMed Central and take full advantage of:

- Convenient online submission

- Thorough peer review

- No space constraints or color figure charges

- Immediate publication on acceptance

- Inclusion in PubMed, CAS, Scopus and Google Scholar

- Research which is freely available for redistribution

Submit your manuscript at www.biomedcentral.com/submit 